\title{
WAVE DYNAMICS AND ITS IMPACT TO WAVE CLIMATE PROJECTION
}

\author{
Tomoya Shimura ${ }^{1}$, Nobuhito Mori $^{2}$, Tomohiro Yasuda ${ }^{2}$ and Hajime Mase ${ }^{2}$
}

\begin{abstract}
Impacts and adaptations of climate change have been studied in various fields. In order to assess the impacts of climate change on coastal areas, it is necessary to evaluate how wave change due to the climate changes. Projections of global wave climate have been carried out by some research groups for next IPCC report. Projection of wave climate contains uncertainties, such as scenario uncertainty, GCM uncertainty and wave model uncertainty. The uncertainties need to be estimated for reliable projections. In this study, wave model uncertainty was evaluated. Global wave hindcasts were conducted using SWAN with four different models of source terms and the impacts of different wave models on global long-term wave statistics were made clear. Furthermore, the global characteristics of differences in long-term wave statistics due to different models were compared with the result of global wave climate projection (Mori et al., 2010). Global long-term wave statistics are varied depending on choice of formula of $S_{\text {in }}$ and $S_{\mathrm{wc}}$ rather than that of $S_{n l 4}$. The uncertainty is larger in eastern lower latitude of ocean especially in the Pacific where swells dominate. On the other hand, the uncertainty of future wave climate change due to wave model is negligibly small in higher latitude where wind-waves dominate.
\end{abstract}

Keywords: wave climate projection; climate change; wave model; uncertainty

\section{INTROCUTION}

Impacts and adaptations of the climate change have been studied in various fields. Sea level rise greatly impacts human activity near coastal zones (IPCC, 2007), and amplifies the vulnerability of coastal regions. From 1870 to 2004, global sea level has risen by $1.7 \pm 0.3 \mathrm{~mm} /$ year (IPCC, 2007). On the other hand, ocean waves give more complex dynamic impacts than sea level rise to coastal and ocean structures, beach morphology, ecosystem and so on. In order to assess the impacts of climate change on coastal areas, it is necessary to evaluate how wave climates change due to the climate changes.

Wave climate has long-term trend or variability (decadal or multi-decadal) associated with climate change. Long-term change of past wave climate has been reported by several researchers. Wang and Swail (2002) showed that trend of annual maxima of wave height in North Atlantic past four decades was $5 \mathrm{~cm} /$ year. Menéndez et al. (2008) reported significant positive long-term trends in observed extreme wave heights between $30^{\circ}-45^{\circ} \mathrm{N}$ latitude near western coasts of the USA. Wave climate can be expected continuously to change corresponding to climate change.

Projections of global wave climate have been carried out by some research groups for next IPCC report in 2013. Wang and Swail (2006) projected global wave climate change using a statistical downscaling method. Mori et al. (2010) carried out projection of global wave climate at the end of $21 \mathrm{st}$ century using dynamical downscaling method, and showed clear future change in averaged wave heights. Hemer et al. (2011) compared global wave projections carried out by 5 international groups each other. The ensemble projection of future change in averaged $H s$ is up to about $0.3 \mathrm{~m}$. The increase in significant wave heights over the Antarctic Ocean seems to be robust. However, standard deviations in ensemble wave climate projections are larger than projected future change over the vast area except for the Antarctic Ocean.

Each global wave projection is based on different scenarios, different Global Climate Models (GCM) and different downscaling approaches for wave climate. These choices of scenario, GCM and wave model lead to variations for wave climate projection. This is uncertainty of wave climate projection, and needs to be evaluated. The uncertainty in scenario for wave climate projections has been evaluated (Wang and Swail, 2006; Charles et al., 2012). They indicated the future changes under higher and lower emission scenario are similar in spatial pattern but different in amplitude. Uncertainty in GCM is larger than the scenario uncertainty (Wang and Swail 2006). GCM uncertainties are differences in amplitude and spatial pattern. As for uncertainty in downscaling approach for wave climate, there is a previous study evaluating the differences between physical and statistical wave model, however, uncertainty by different physical wave models is not clear. Therefore, the objective in this study is to estimate uncertainties in wave projection by different physics in wave model such as source terms.

\footnotetext{
${ }^{1}$ Graduate School of Engineering, Kyoto University, Katsura, Nishikyoku, Kyoto 615-8530, JAPAN

2 Disaster Prevention Research Institute, Kyoto University, Gokasho, Uji, Kyoto 611-0011, JAPAN
} 


\section{METHODOLOGY}

Global wave hindcasts were carried out based on sea surface wind $\left(U_{10}\right)$ from European Center for Mid-Weather Forcast's (ECMWF's) ERA-40 re-analysis (Uppala et al., 2006) and wave model SWAN version 40.85 (Booij et al., 1999) changing wave physical settings. Computations were conducted in periods of 1995 to 1997 and 1999 to 2001, using a spherical coordinate with 1 degree spatial resolution, driven by 6-hourly ERA-40's $U_{10}$ whose spatial resolution is 2.5 degree. Spectral space was discretized with 25 frequencies from $0.04 \mathrm{~Hz}$ to $0.5 \mathrm{~Hz}$ and 36 directions.

In deep water, the spectral energy $(E)$ balance which is governing equation of SWAN is written as

$$
\frac{D E}{D t}=S_{i n}+S_{w c}+S_{n l 4}
$$

where $S_{i n}, S_{w c}$ and $S_{n l 4}$ represent the processes of wave generation by wind, dissipation by white-capping and quadruplet wave-wave interaction, respectively. $S_{i n}$ and $S_{w c}$ are formulated under several empirical assumptions. Therefore, processes of $S_{i n}$ and $S_{w c}$ are treated in several formulas, which require combination of different source terms. In this study, two major formulas for $S_{i n}$ and $S_{w c}$ are adopted for the evaluation. One is $S_{\text {in }}$ modeled by Komen et al. (1984) with $S_{w c}$ of WAM Cycle III formulation (Komen et al., 1984), which is default combination in SWAN model. The other is $S_{i n}$ involving wavewave interactions (Janssen, 1991) with $S_{w c}$ of WAM Cycle IV formulation (Gunther et al., 1992). These two formulas for $S_{i n}$ and $S_{w c}$ are denoted as KOM and JAN hereafter, respectively.

On the other hand, the wave interaction process of $S_{n l 4}$ is mathematically well understood. However, the exact computation of $S_{n l 4}$ requires huge computational cost. In operational wave model, approximate expression of $S_{n l 4}$ is used generally. Discrete Interaction Approximation (DIA) proposed by Hasselmann (1984) is used commonly for many wave models. Global Ocean is strongly dominated by swell waves (Semedo et al., 2011) and swell requires the accurate computation of non-linear wavewave interaction because existence of swell makes shape of wave spectrum become complex. Thus, in addition to DIA, more accurate approximation method of $S_{n l 4}$, Multiple DIA (MDIA; Hashimoto and Kawaguchi, 2001) was applied for global wave simulation. The computation of full nonlinear wave interactions (XNL) is getting popular for research but it is still expensive to use in global scale.

Global wave simulations were conducted using SWAN with four different model settings consisting of two formulas for $S_{i n}$ and $S_{w c}$, of JAN and KOM, and two approximation methods of $S_{n l 4}$, of DIA and MDIA. Four different model settings are denoted as JAN+DIA, JAN+MDIA, KOM+DIA and KOM+MDIA, respectively. Target wave statistics are long-term averaged significant wave height $\left(H_{s}\right)$, mean wave period $\left(T_{m}\right)$, mean wave direction (Dir) and 99\% quantile of $H_{s}$. These wave statistics computed by different settings are compared with each other. There are several studies investigated the differences in wave statistics due to different model settings in short period such as a few days during tropical storm passing. In order to estimate the uncertainty of wave climate projection, long-term (annual) wave statistics are focused.

Finally, the global characteristics of differences in long-term wave statistics due to different model settings are compared with the result of global wave climate projection (Mori et al., 2010) and the uncertainty of global wave climate projection is evaluated.

Table 1. List of source terms for validation

\begin{tabular}{|l|l|l|}
\hline Source term & Model & Notation \\
\hline$S_{\text {in }}$ & Komen et al. (1984) & KOM \\
\hline & Janssen (1991) & JAN \\
\hline$S_{n l 4}$ & Hasselman (1984) & DIA \\
\hline & Hashimoto and Kawaguchi (2001) & MDIA \\
\hline
\end{tabular}

\section{RESULTS AND DISCUSSION}

At first, averaged $H_{s}, T_{m}$ and Dir for 3 years from 1995 to 1997 simulated by SWAN with JAN+DIA setting are shown in Figure 1-3 respectively. The spatial characteristics of averaged $H_{s}, T_{m}$ 
and Dir and difference of source terms for the long-term wave climate projection will be discussed in this section.

$H_{s}$ are larger at higher in latitude corresponding to strong westerly wind (Figure 1). $H_{s}$ in the Antarctic Ocean are the largest, which is about $3.5 \mathrm{~m} . T_{m}$ are longer in the Antarctic, lower latitude and eastern part of the north Pacific because of swell propagating from higher latitude (Figure 2). In Atlantic, $T_{m}$ are shorter comparing with the Pacific. $\boldsymbol{T}_{\boldsymbol{m}}$ at western sea of Mexico are the longest, which is about $8 \mathrm{~s}$. Waves propagate westward in $40^{\circ} \mathrm{S}-40^{\circ} \mathrm{N}$ and eastward in higher latitude than $40^{\circ}$ (Figure 3).

\section{Difference in $\boldsymbol{H}_{\boldsymbol{s}}$}

Figure 4 shows differences in averaged $H_{s}$ by JAN+DIA and KOM+DIA. Over the globe, averaged $H_{s}$ by JAN+DIA have tendency to be larger than those by KOM+DIA. Especially, in eastern part of the Pacific Ocean, the differences are significant and up to $0.8 \mathrm{~m}$. These differences are mainly caused by an accuracy of swell. Simple fetch limited numerical experiments shows that spectrum of wave calculated by JAN have a steeper peak at longer wave period than those of KOM (not shown), which can generate larger and less dispersive swell. Therefore, the differences become larger in eastern of ocean basin due to effect of larger swell components. Spatial distribution of differences (Figure 4) is similar to that of "swell pool" in Chen et al. (2002). Therefore, differences are remarkable in swell dominant region which is the eastern part of ocean basin.

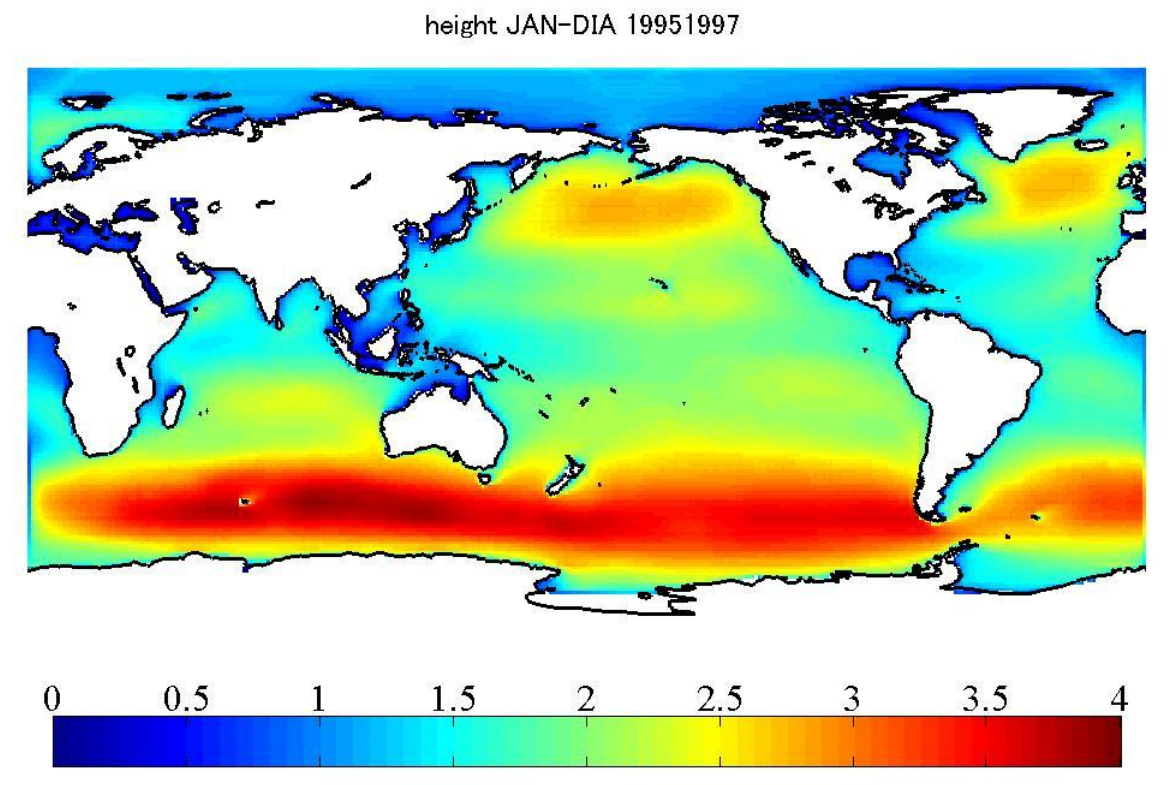

Figure 1. 3 years averaged $H_{s}$ simulated by SWAN with JAN+DIA setting 
period JAN-DIA 19951997
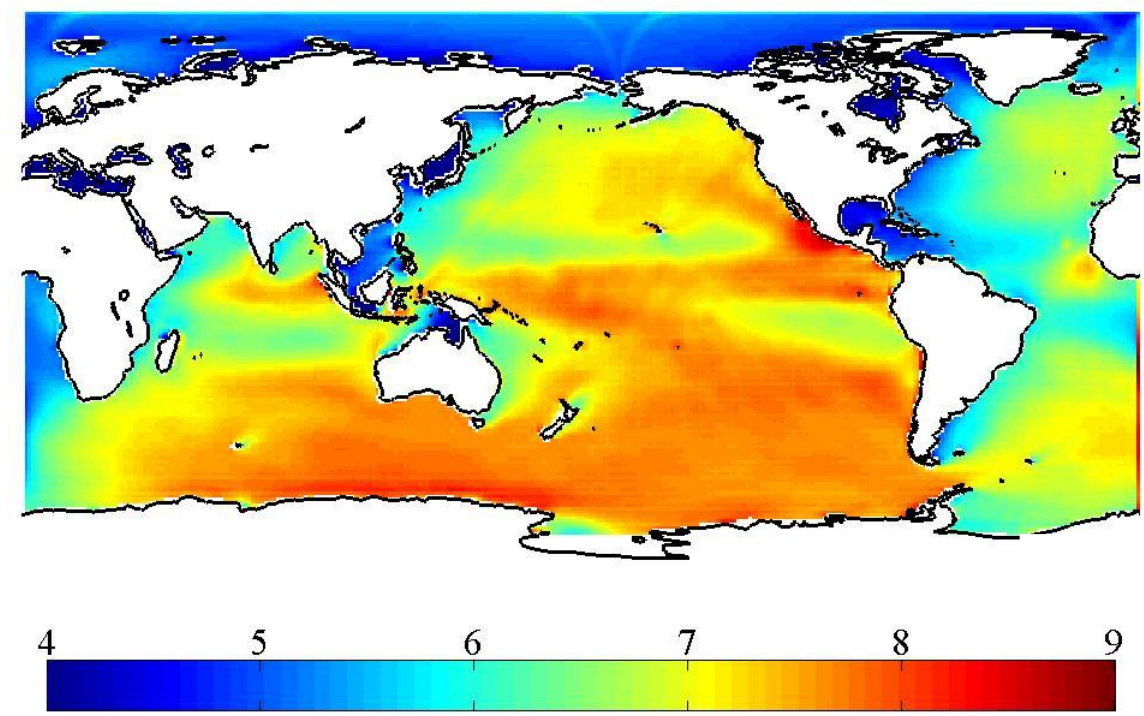

Figure 2. 3 years averaged $T_{m}$ simulated by SWAN with JAN+DIA setting

direction JAN-DIA 19951997

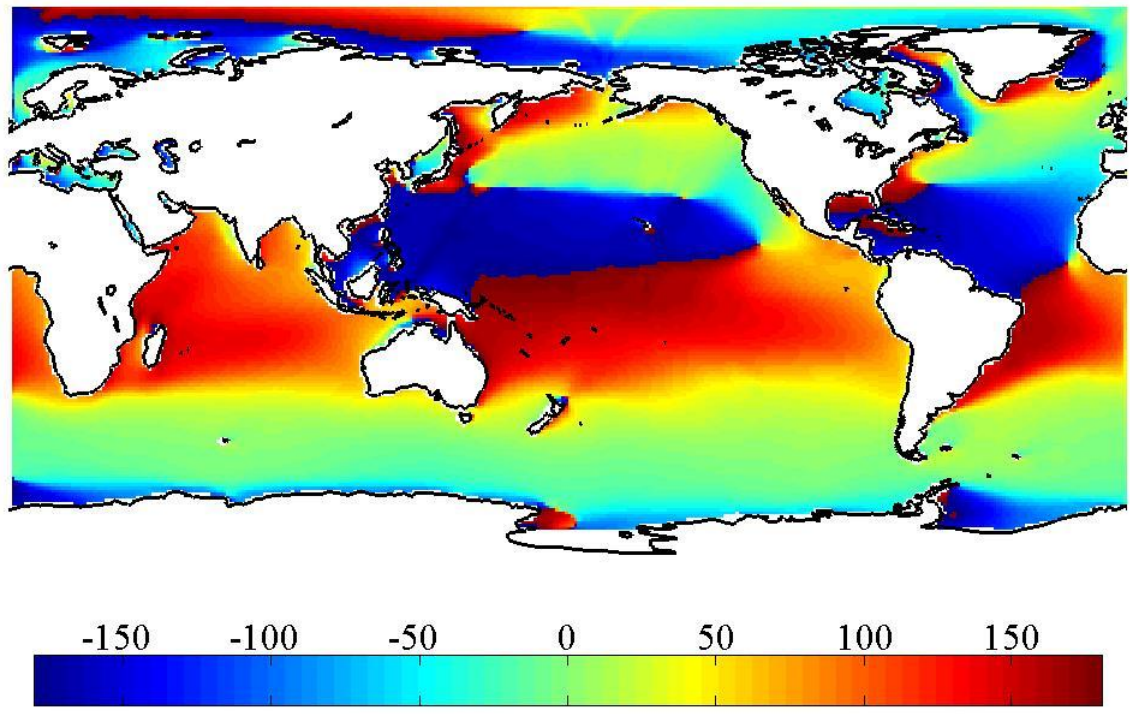

Figure 3. 3 years averaged Wave direction simulated by SWAN with JAN+DIA setting (nautical coordinate) 


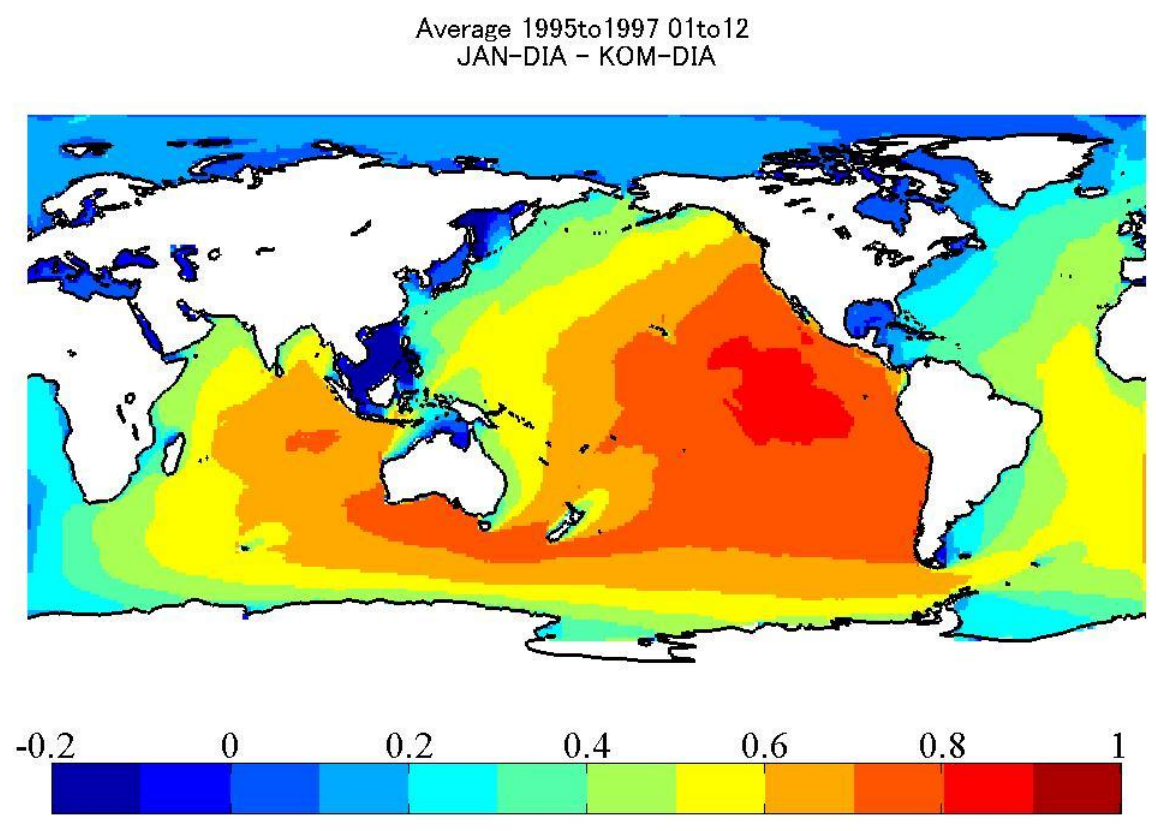

Figure 4. Differences in 3 years (1995-1997) averaged $\boldsymbol{H}_{s}$ calculated by JAN+DIA and KOM+DIA (JAN+DIA - KOM+DIA)

For extreme wave climate, differences in 99\% quantile of $H_{s}$ calculated by JAN+DIA and KOM+DIA are similar to those of averaged value spatially (not shown). The differences are up to $1 \mathrm{~m}$ at lower latitude in the eastern Pacific. On the other hand, averaged value and 99\% quantile of $H_{s}$ calculated by DIA are similar to those by MDIA. It was found that MDIA doesn't influence on longterm wave statistics such as $H_{s}, T_{m}$ and Dir significantly in global scale, comparing with DIA. Therefore, differences of wind energy input between KOM and JAN are focused hereafter.

For the validation, the simulated wave heights were compared with buoy observations. As an example, the results of comparison with buoy at the northwest of Hawaii (\#51001), obtained from National Oceanic and Atmospheric Administration's National Data Buoy Center (NOAA, NDBC), is shown in Figure 5. The comparison was conducted by Quantile-Quantile plot of 1 to 99 percentiles in 1995. Although the simulated values are underestimated totally, but wave heights calculated by JAN show better agreement with observation than those of KOM. The comparisons with other buoy observations showed the similar results.

\section{Difference in $T_{m}$}

Figure 6 shows differences in 3 years averaged $T_{m} . T_{m}$ by JAN+DIA is clearly longer than that of KOM+DIA especially in the lower latitude and the eastern part of ocean basin which is swell dominant area. 3-year (1995 - 1997) averaged $T_{m}$ of buoy observation at the northwest of Hawaii (NOAA/NDBC \#51001), the eastern North Pacific (\#46003), and east of Florida (\#41010) are 6.8s, 7.2s and 5.6s respectively (obtained from "The KNMI/ERA-40 WAVE ATLAS", http://www.knmi.nl/waveatlas). $T_{m}$ by JAN+DIA at the three locations are 7.2s, 7.2s and 5.2s. Those of KOM+DIA are $4.6 \mathrm{~s}, 4.7 \mathrm{~s}$ and $3.6 \mathrm{~s}$. Therefore, $T_{m}$ by JAN+DIA is plausible rather than KOM+DIA, considering observation.

\section{Difference in Dir}

Figure 7(a) shows 3 years averaged Dir by JAN+DIA and KOM+DIA. Differences in Dir are also significant at swell dominant regions which are lower latitude in eastern part of the Pacific. Figure 7(b) shows 3-year averaged Dir, focusing on lower latitude in eastern part of the Pacific Ocean. In the Antarctic Ocean, directions by JAN and KOM are almost same. However, in lower latitude, wave 
directions by JAN are more eastward than those of KOM. Wave directions by JAN are closer to direction of swell propagation which is generated in the Antarctic Ocean and propagates north-eastward. On the other hand, wave directions by KOM correspond well to wind direction which is westward.

\section{Difference in Periodic change of $\boldsymbol{H}_{s}$}

The wave statistics itself are important but also the changes of wave statistics are important for projection of future wave climate. Therefore, we evaluate the periodic changes of average $H_{s}$ from the period 1995-1997 to the period 1999 to 2001. Periodic change of averaged $H_{s}$ by JAN+DIA is shown in Figure 8. The $H_{s}$ increases at higher latitude and lower latitude in the Pacific, and decrease at mid latitude in the Northern Hemisphere. The range of change is about $-0.25 \mathrm{~m}$ to $+0.25 \mathrm{~m}$. Figure 9 indicates the differences in periodic change of $H_{s}$ between JAN+DIA and KOM+DIA. The differences are larger in eastern part of the Pacific Ocean and those are about -0.02 to $+0.06 \mathrm{~cm}$. Differences at eastern lower latitude in the Pacific Ocean correspond to $100 \%$ of periodic change by JAN+DIA. This difference is also caused by swell effect. Increases in averaged $H_{s}$ in higher latitude of the Pacific (Figure 8) reads to increase in swell heights in eastern lower latitude. The increase in swell height by JAN+DIA is larger than KOM+DIA. This is why the differences in periodic change are larger in the swell dominant region. Nevertheless, the periodic change is relatively larger in higher latitude which is wind-wave dominant area, the differences in periodic change are negligibly small.

\section{Comparing with projection of future wave climate}

Mori et al., (2010) conducted projection of future wave climate in the end of 21 st century under global warming condition using MRI Atmospheric General Circulation Model (MRI-AGCM-3.1S) for CMIP5 and SWAN. Figure 10 is the result of projected future change of averaged $H_{s}$ from the period 1979 to 2003 to the period 2075 to 2099 . This projection was based on SWAN with JAN+DIA setting. This future change was up to $0.3 \mathrm{~m}$. This future change is characterized by increase in the Antarctic Ocean and decrease in the mid-latitude area. This future change is almost same order as the short-term periodic change as shown in Figure 8. Even though this future change (Figure 10) is based on 25 years average and the periodic change (Figure 8) is based on 3 years average, this future change can be considered to become smaller especially at eastern lower latitude of the Pacific Ocean by about $0.05 \mathrm{~m}$, if using KOM+DIA instead of JAN+DIA because the increase in wave heights at the Antarctic Ocean reads to less increase in swell height at lower latitude than that of JAN+DIA. On the other hands, in the wind-wave dominant region which is higher latitude, future change is not expected to be varied depending on KOM+DIA or JAN+DIA.

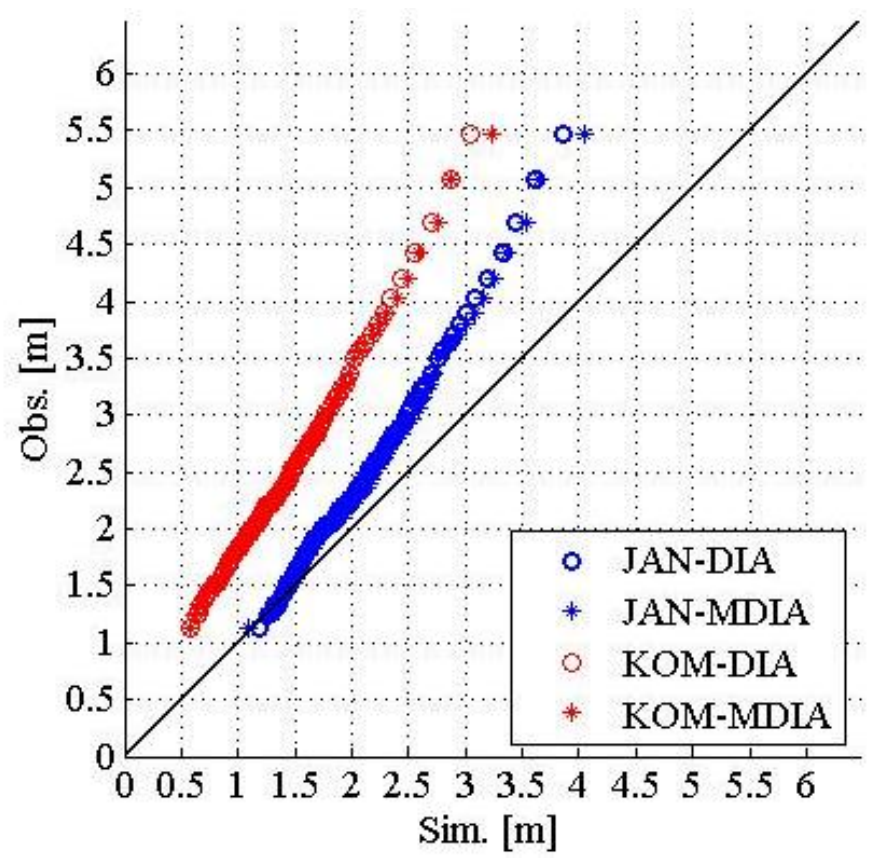

Figure 5. Quantile-Quantile plot for comparison with buoy at Northwest of Hawaii (NOAA/NDBC \#51001) 
Average 1995to1997 01to12

JAN-DIA - KOM-DIA
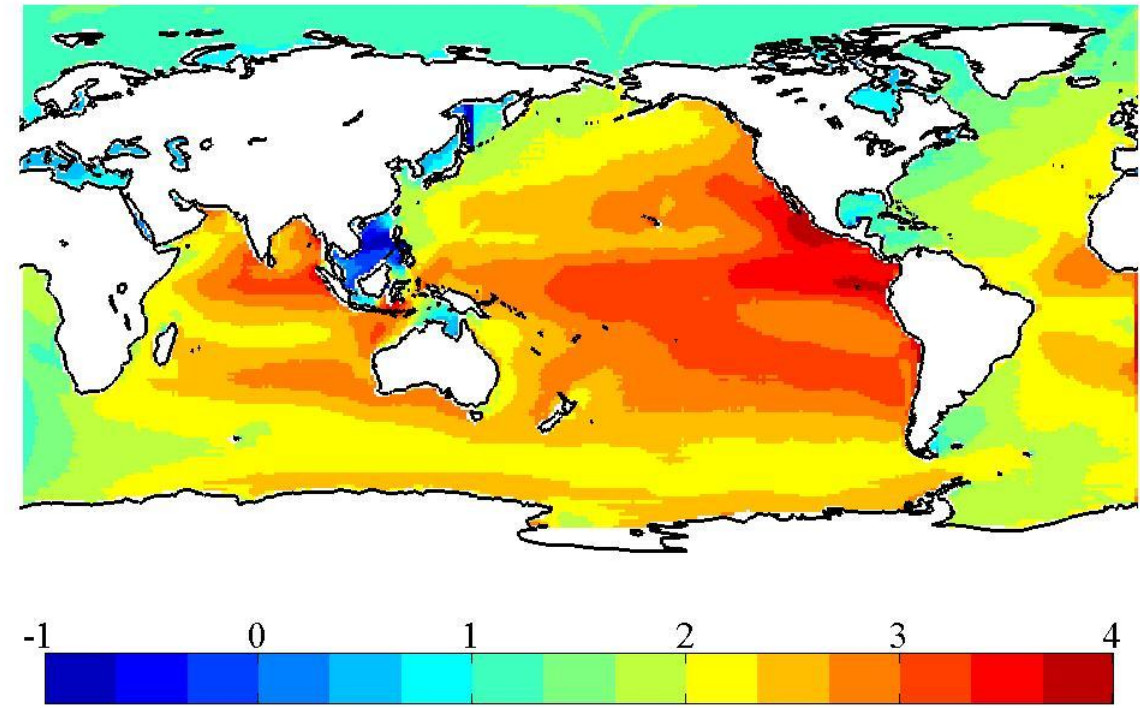

Figure 6. Differences between 3 years (1995-1997) averaged $T_{m}$ calculated by JAN+DIA and KOM+DIA (JAN+DIA - KOM+DIA)

Average 1995to1997 01to12

JAN-DIA - KOM-DIA

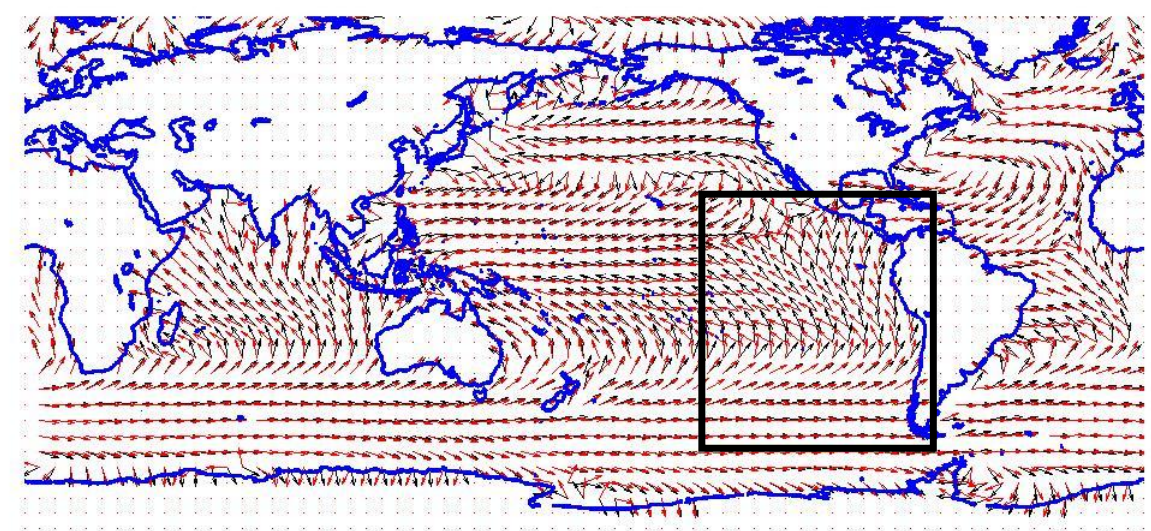

$\begin{aligned} \longrightarrow & \text { JAN-DIA } \\ & >\text { KOM-DIA }\end{aligned}$

(a) Global view 


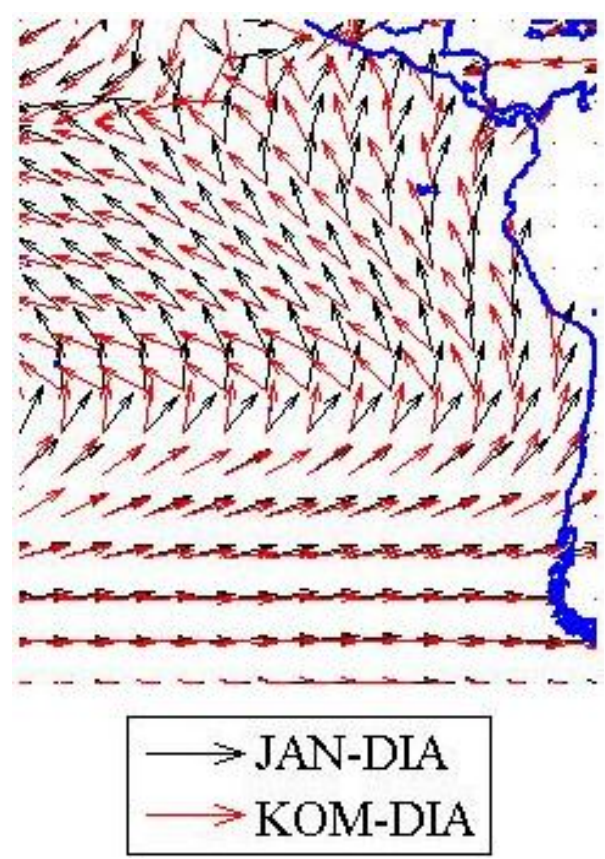

(b) Focusing on the south eastern Pacific Ocean

Figure 7. 3 years (1995-1997) averaged Dir calculated by JAN+DIA and KOM+DIA

Average JAN-DIA(99-01) - JAN-DIA(95-97)

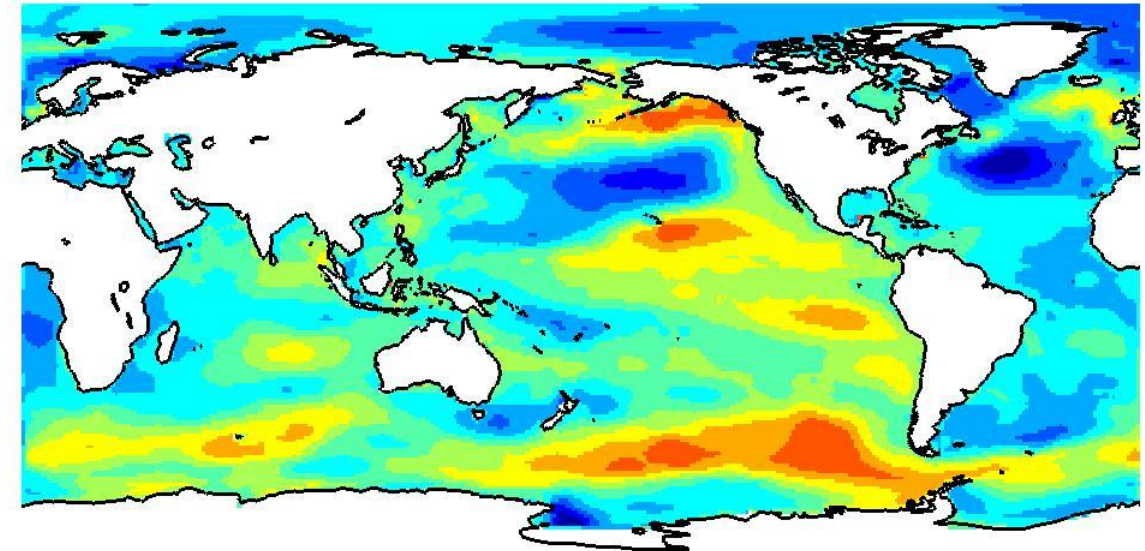

$\begin{array}{llllllllll}-0.25 & -0.2 & -0.15 & -0.1 & -0.05 & 0 & 0.05 & 0.1 & 0.15 & 0.2\end{array}$

Figure 8. Changes of average $H_{s}$ by JAN+DIA from period 1995-1997 to period 1999 to 2001 
Average JAN-DIA--KOM-DIA((99to01-95to97)

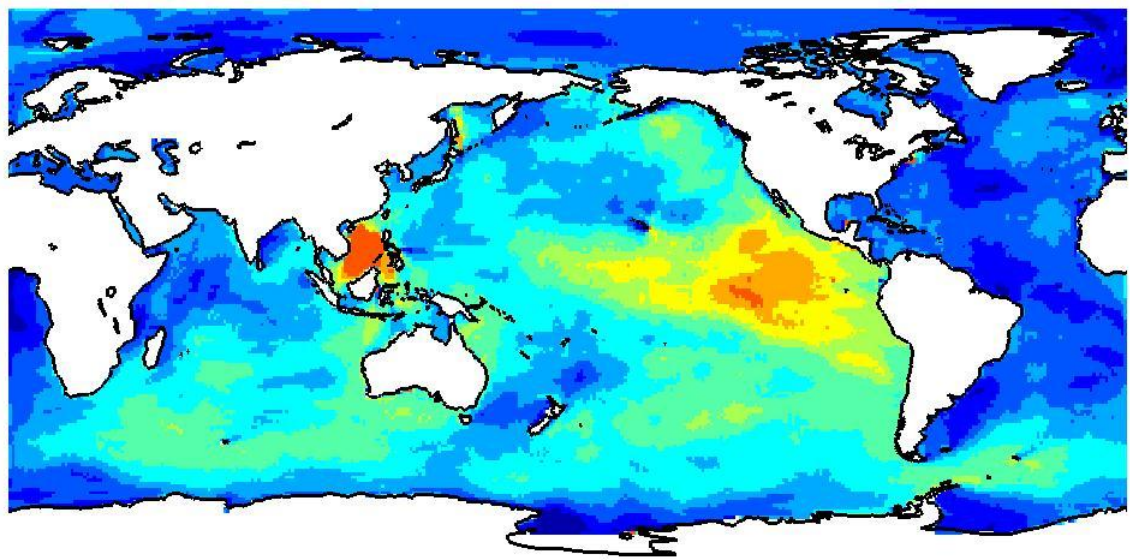

$-0.02$

0

0.02

0.04

0.06

Figure 9. Difference between Changes of average $H_{s}$ from period 1995-1997 to period 1999 to 2001 calculated by JANL+DIA and KOM+DIA (JAN+DIA - KOM+DIA)
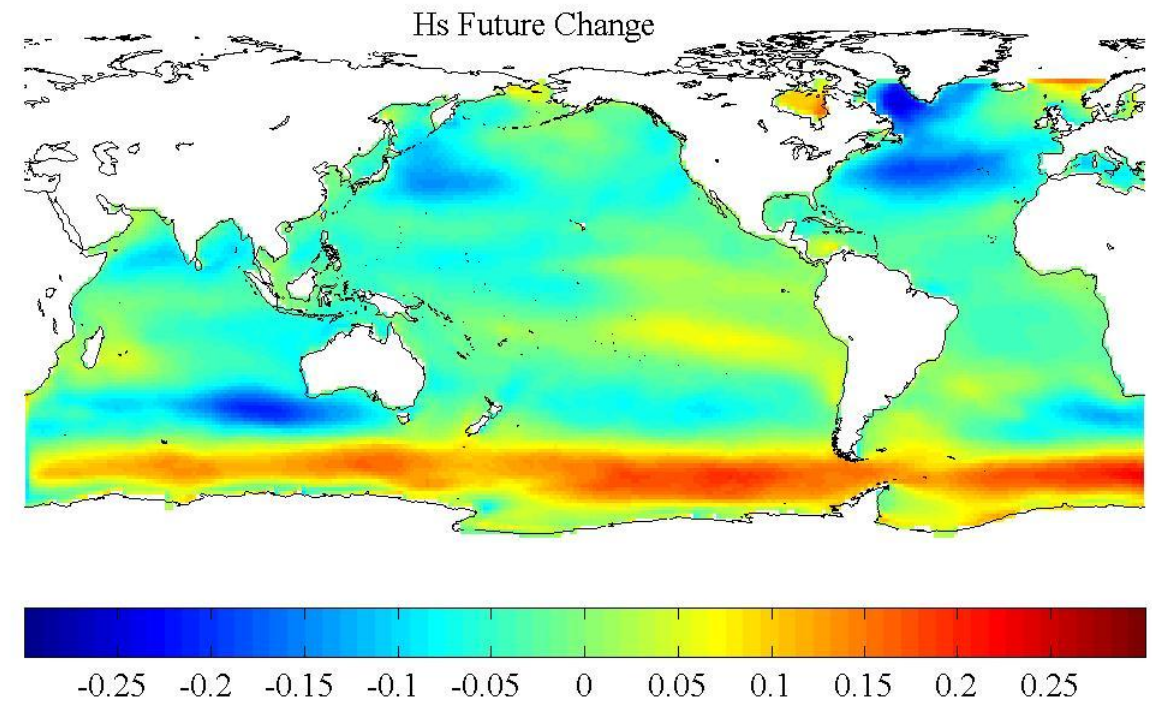

Figure 10. Projected future change of $H_{s}$ from period $1979-2003$ to period 2075 - 2099 


\section{CONCLUSIONS}

Global wave simulations were conducted using ERA-40 reanalysis wind and wave model SWAN with four different model configurations, consisting of two formulas for $S_{i n}$ and $S_{w c}$, and two approximation methods for $S_{n l 4}$, in order to estimate the uncertainty of projection of future global wave climate arising from wave models. The global long-term wave statistics are found to be varied depending on choice of formula of $S_{i n}$ and $S_{w c}$ rather than that of $S_{n l 4}$. The differences of long-term wave statistics due to choice of formula of $S_{i n}$ and $S_{w c}$ are larger in eastern lower latitude of ocean basin especially the Pacific where swells dominate. The difference in 3 years averaged $H_{s}$ between JAN and $\mathrm{KOM}$ is up to $0.8 \mathrm{~m}$. The differences are caused by difference in numerical accuracy of swell component. The swell calculated by JAN is larger in height and less dispersive than KOM. $T_{m}$ by JAN is clearly longer than that of KOM. The wave directions, Dir, in eastern lower latitude are varied depending on JAN or KOM due to difference in swell.

Periodic change of $H_{s}$ calculated by JAN is different with that by KOM in swell dominant region. However, despite the fact that difference in averaged $H_{s}$ between $\mathrm{KOM}$ and JAN is relatively large in part of wind-wave dominant region, about $0.8 \mathrm{~m}$, the difference is negligibly small. Therefore, uncertainty in future change of wave climate at higher latitude arising from wave model is small, but the uncertainty at lower latitude, especially eastern part of ocean basin, is relatively large.

Recent studies of future wave climate projection by Mori et al. (2010) and Hemer et al. (2011) show that the increase in wave heights over the Antarctic Ocean where energetic swells are generated. Therefore swell in lower latitude would larger in the future climate corresponding to increase in wave heights in the Antarctic Ocean. However the rate of increase in swell at lower latitude is varied depending on wave model.

Swell and wind-wave have different characteristics. In addition, the extent of uncertainty in future change between swell and wind-wave is different. Therefore, projection of future wave climate requires estimation of wave climate dividing swell and wind-wave such as the work of Semedo et al. (2011). Furthermore, not only SWAN but also other common wave models such as WAVE WATCH III (Tolman, 2009) are used and the uncertainty due to wave model need to be evaluated.

\section{ACKNOWLEDGMENTS}

This work was supported by JSPS Research Fellowship for Young Scientist, Grant-in-Aid for JSPS Fellows, Grants-in-Aid for Scientific Research by JSPS and partly supported by NSFC Grant (No. 51010009).

\section{REFERENCES}

Booij, N. R.C. Ris and L.H. Holthuijsen. 1999. A third-generation wave model for coastal regions. IModel description and validation, Journal of geophysical research, 104(C4), 7649-7666.

Caires. S, A. Sterl, G. Komen and V. Swail. The KNMI/ERA-40 WAVE ATLAS, http://www.knmi.nl/waveatlas

Charles, E., D. Idier, P. Delecluse, and M. Delecluse and G.L. Cozannet. 2012. Climate change impact on waves in the Bay of Biscay, France, Ocean Dynamics, 62, 831-848.

Chen, G., B. Chapron, R. Ezraty and D. Vandemark. 2002. A global view of swell and wind sea climate in the ocean by satellite altimeter and scatterometer, Journal of Atmospheric and Oceanic Technology, 19 (11), 1849-1859.

Gunther, H., S. Hasselmann and P.A.E.M. Janssen. 1992. The WAM Model Cycle 4, Technical report No. 4.

Hashimoto, N., and K. Kawaguchi. 2001. Extension and modification of discrete interaction approximation (DIA) for computing nonlinear energy transfer of gravity wave spectra, Proceedings of International Conference on Coastal Engineering, ASCE, 530-539.

Hasselmann, S., K. Hasselmann, J.H. Allender and T.P. Barnett. 1985. Computations and parametrizations of the nonlinear energy transfer in a gravity-wave spectrum. ii: Parametrizations of the nonlinear energy transfer for application in wave models. Journal of Physical Oceanography, 15, 1378-1391.

Hemer, M., X.L. Wang, V.R. Swail, R. Weisse and DOWCLIP-Team. 2011. Coordinated Ocean Wave Climate Projections (COWCLIP), 12th International Workshop on Wave Hindcasting and Forecasting.

IPCC. 2007. IPCC fourth assessment report (AR4). http://www.ipcc.ch/. 
Janssen, P.A.E.M. 1991. Quasi-linear theory of wind-wave generation applied to wave forecasting, $J$. Phys.Oceanogr, 21, 1631-1642.

Komen, G.J., S. Hasselmann, and K. Hasselmann. 1984. On the existence of a fully developed wind-sea spectrum, J. phys. Oceanogr, 14, 1271-1285.

Menéndez, M., F. J. Méndez, I. J. Losada, and N. E. Graham. 2008. Variability of extreme wave heights in the northeast Pacific Ocean based on buoy measurements, Geophys. Res. Lett., 35, L22607.

Mori, N., T. Yasuda, H. Mase, T. Tom and Y. Oku. 2010. Projection of extreme wave climate change under global warming, Hydrological Research Letters, 4, 15-19.

Semedo, A., K. Suselj, A. Rutgersson and A. Sterl. 2011, A global view on the wind sea and swell climate and variability from ERA-40, Journal of Climate, 24, 1461-1479.

Tolman, H.L. 2009. User manual and system documentation of wavewatch III version 3.14, NOAA/NWS/NCEP/MMAB Technical Note, 276.

Uppala, S.M. and P.W. Kallberg, A.J. Simmons, U. Andrae, V. Bechtold, M. Fiorino, J.K. Gibson, J. Haseler, A. Hernandez, G.A. Kelly et al. 2005. The ERA-40 re-analysis, Quarterly Journal of the Royal Meteorological Society, 131(612), 2961-3012

Wang, X.L., and V.R. Swail. 2002. Trends of Atlantic wave extremes as simulated in a 40-Yr wave hindcast using kinematically reanalyzed wind fields, Journal of climate, 15(9), 1020-1035.

Wang., X.L., and V.R. Swail. 2006. Climate change signal and uncertainty in projections of ocean wave heights, Climate Dynamics, 29(2), 109-126. 